\section{Role for deep hypothermic circulatory arrest during repair of heart defects in infants}

\section{To the Editor:}

The remarks made by Dr Frank Hanley, as a discussion to the paper presented by Dr Frank Pigula at the meeting of The Western Thoracic Surgical Association (J Thorac Cardiovasc Surg 2000;119:331-9), should not be left without commentary.
In his discussion, Dr Hanley intimates that time, effort, and money spent evaluating cerebral response to cardiopulmonary bypass $(\mathrm{CPB})$ and its various strategies, especially the strategy of deep hypothermic circulatory arrest (DHCA), are misplaced. I think it is critical that we as surgical colleagues, especially since we do influence scores of others in related disciplines, remain objective when making these kind of public proclamations. The same kind of reasoning would have led previous investigators in the field of myocardial protection to abandon as misplaced the phenomenal efforts relating to cardioplegic protection of the heart during the ischemia induced by an aortic crossclamp. If the heart is allowed to electrically fibrillate, it remains perfused; therefore, this technique would appear to be superior to inventing ways to protect the heart from ischemia. Armchair reasoning led many to believe that fibrillation of the heart would be superior to any form of protection from induced ischemia. Carefully constructed investigation-a hallmark of surgical progressdemonstrated that cardioplegic protection of the heart might be better. Because of research, aortic crossclamping and protection with cardioplegia is safe for long periods of time and is a shining example of how investigation can help us improve our systems to optimize outcome for patients.

The fact that the brain is a more complex organ than the heart, with functionality that we will never learn how to evaluate, makes it that much more difficult to determine the right thing to do for our patients. There is excellent work (clinical and experimental) to demonstrate the deleterious effects of prolonged exposure to hypothermic low-flow CPB on brain architecture, as well as on total body fluid accumulation and pulmonary compliance. ${ }^{1-3}$ Despite armchair reasoning, continuous low-flow bypass may not always be the best option.

Because of all the investigation that has been performed relating to cerebral response to $\mathrm{CPB}$ and DHCA, our patients today are experiencing outstanding outcomes. Application of these strategies has changed considerably since the days of what Dr Hanley referred to as "pioneers." There are still times when DHCA is a useful option for the surgeon when repairing congenital defects. Rather than have it be abandoned at all costs, perhaps we should just learn to apply it appropriately. Recent data suggest that periods of intermittent perfusion during periods of $\mathrm{DHCA}^{4}$ may provide the best brain protection of all available strategies. This technique, which is supported by elegant research, may reduce some of the complications related to continuous low-flow perfusion while still providing the surgeon with the advantages of simple CPB cannulation and a bloodless field unencumbered by cannulas during critical periods of an operative repair.

I truly do not know what system is the best to use for infants undergoing repair of complex heart defects. I suspect that we as surgeons need to keep our minds open and be flexible enough to recognize that there are many options available to us that can be tailored to the challenges presented by each individual patient. Future research will help us refine these techniques even more. Outcomes after repair of heart defects are the best they have ever been, and I believe that it 
is because of our ability to be open minded, ask important questions, and then objectively investigate what we do.

Ross M. Ungerleider, MD

Professor of Surgery

Chief, Pediatric Cardiac Surgery

Duke University Medical Center

Durham, NC 27710

\section{REFERENCES}

1. Wernovsky G, Wypij D, Jonas RA, Mayer JE Jr, Hanley FL, Hickey PR, et al. Postoperative course and hemodynamic profile after the arterial switch operation in neonates and infants: a comparison of low-flow cardiopulmonary bypass and circulatory arrest. Circulation 1995;92:2226-35.

2. Skaryak LA, Lodge AJ, Kirshbom PM, DiBernardo LR, Wilson BG, Meliones JN, et al. Low flow cardiopulmonary bypass produces greater pulmonary dysfunction than circulatory arrest. Ann Thorac Surg 1996;62:1284-8.

3. Scheller MS, Branson PJ, Cornacchia LG, Alksne JF. A comparison of the effects on neuronal golgi morphology, assessed with electron microscopy, of cardiopulmonary bypass, low-flow bypass, and circulatory arrest during profound hypothermia. $\mathbf{J}$ Thorac Cardiovasc Surg 1992;104:1396-404.

4. Langley S, Chai PJ, Miller SE, Mault JR, Jaggers J, Tusi SS, et al. Intermittent perfusion protects the brain during deep hypothermic circulatory arrest. Ann Thorac Surg 1999;68:4-13.

[Comment declined]

12/8/108282

doi: $10.1067 / \mathrm{mtc} .2000 .108282$ 